\title{
3D SIMULATION OF THE FLUTED MIXER ELEMENT BEHAVIOR
}

\author{
Pavel Kubik, Department of Polymer Engineering, Faculty of Technology, Tomas Bata University in \\ Zlín, Zlín, Czech Republic.
}

Jiri Vlcek and Jiri Svabik, Compuplast International, Inc., Zlín, Czech Republic

Martin Zatloukal, Polymer Centre, Faculty of Technology, Tomas Bata University in Zlín, Zlín, Czech

\begin{abstract}
One of the most important, yet problematic, issues in the extrusion process is achieving good mixing. Considerable prior efforts have been made to understand different types of mixing elements for single-screw and twin-screw extrusion. However, there is still a lack of good process values or criteria that can be used for design purposes. The focus of this work is to better quantify the mixing behavior, using 3D FEM analysis, to develop some design criteria. This study will focus on the fluted mixer, comparing common design variations and the effect of material viscosity and process conditions.
\end{abstract}

\section{Introduction}

Mixing elements can be viewed as unknown and mysterious parts of plastics industry. Therefore, it is not surprising that considerable effort is done to study different types of mixing elements in single-screw [1-3] and twin-screw [411] extrusion. Even if many useful conclusions can be extracted from the open literature, full understanding of mixing elements behavior is still not available.

Another aspect, very important in study of mixing elements, is practical knowledge of experienced workers but reality can be different.

In this paper, a deep attention is focused on a fluted mixing element widely used in the plastics industry. Two slightly different designs are studied. One type is much easier to manufacture and many people believe that this geometry change has very little impact on its performance.

For this purpose, a full 3D Finite Element Method simulation will be utilized to understand the effect of the fluted mixer element in extrusion process.

\section{Methods}

Two types of fluted mixing elements can be seen in Figure 1. The first one, so called a closed mixer, had an undercut on one flight between the channels. The second flight of this mixer does not have an undercut. This flight wipes the surface of the barrel. In this case, the material entered the gap over the undercut only through the inlet channel. The second one, so called an open mixer, had undercuts from both sides of the channels and there was no wiping of the material from the barrel surface. Because of this, the melt did not enter the channel only from the inlet, but also from the side.
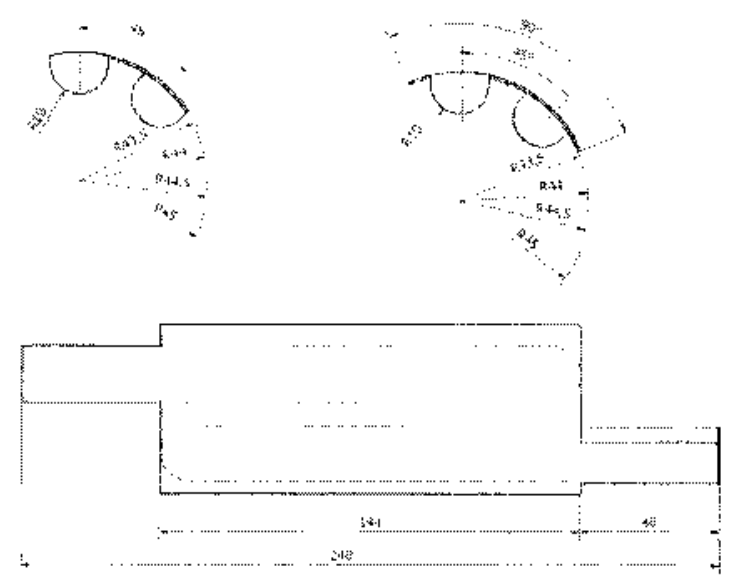

Figure 1. Design of the investigated fluted mixers in closed and open configurations

A basic 3D FEM grid was generated by a fluted mixer template, which is a special part of the VEL ${ }^{\mathrm{TM}}$ software [12]. Now, the grid was refined especially in the comers and along the length to minimize the computational errors and to increase the numerical stability. The diameter of the mixer analyzed was $90 \mathrm{~mm}$ 
and three different undercut gaps, 0.5 - 1.0 - $1.5 \mathrm{~mm}$, were used for the numerical analysis. Both fluted mixers were tested under the same process conditions specified in Table 1 .

Table 1. Process conditions

\begin{tabular}{|l||ccc|}
\hline Screw Rotations [lpm] & 30 & 60 & 90 \\
\hline Mass Flow Rate [kg/h] & 75 & 150 & 225 \\
\hline
\end{tabular}

\section{Materials}

The main material used for the study was low viscosity LDPE, which was completely predefined in the VEL ${ }^{\mathrm{TM}}$ software material database. The material description is based on the Carreau-Yasuda model, in which the viscosity dependence is decribed by the following equation:

$$
\eta(\dot{\gamma}, T)=\frac{A f(T)}{\left[1+(r \dot{\gamma} f(T))^{a}\right]^{1-\pi}}
$$

Where $A$ is the zero shear viscosity, $a, n, r$ are the constants, the $T$ is temperature and $y$ is the shear rate. The material temperature dependence $f(T)$ is exponential and is given by the following equation:

$$
f(T)=e^{-b\left(T-T_{r}\right)}
$$

The parameter $b$ represents the temperature sensitivity and $T_{r}$ is the reference temperature. The equation parameters and the material properties are summarized in Table 2.

\begin{tabular}{|c|c|c|c|}
\hline \multicolumn{2}{|c|}{ Rheology } & \multicolumn{2}{|c|}{ Thermal Properties } \\
\hline A [Pa.s] & 8000 & \multirow{2}{*}{ 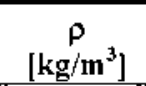 } & \multirow{2}{*}{750} \\
\hline n $[-1$ & 0.17 & & \\
\hline $\mathbf{r}[\mathbf{s}]$ & 0.97 & \multirow{2}{*}{$\begin{array}{c}C \mathrm{p} \\
{[\mathrm{J} /(\mathrm{kg} \cdot \mathrm{C})]}\end{array}$} & \multirow{2}{*}{2300} \\
\hline a $[-]$ & 0.50 & & \\
\hline $\mathrm{T}_{\mathrm{r}}\left[{ }^{\mathrm{D}} \mathrm{C}\right]$ & 200 & \multirow{2}{*}{$\begin{array}{c}\lambda \\
{[w /(\mathbf{m} . \mathbf{k})]}\end{array}$} & \multirow{2}{*}{0.24} \\
\hline b $\left[1 /{ }^{\circ} \mathrm{C}\right]$ & 0.02 & & \\
\hline
\end{tabular}

Table 2. Material properties - LDPE

The material had a very low shear viscosity (its MFI is about 4). It was chosen to eliminate the dissipation during the flow through the element and thus to see the effect of mixing.

The second material used for comparison at the

1. $0 \mathrm{~mm}$ gap was a high viscosity HDPE. Its viscosity is described by the Power-law model. The viscosity equation is:
Where $\mathrm{A}$ is the zero shear viscosity, $y$ is the shear rate, $\mathrm{n}$ is the Power-law constant. The temperature dependence $f(T)$ is the same as for the LDPE material (eq. 2). Values of the Power-law parameters and melt properties can be seen in Table 3 .

\begin{tabular}{|c|c|c|c|}
\hline \multicolumn{2}{|c|}{ Rheology } & \multicolumn{2}{|c|}{ Thermal Properties } \\
\hline $\mathrm{A}[\mathrm{Pa} . \mathrm{s}]$ & 27409 & \multirow{2}{*}{$\begin{array}{c}\rho \\
{\left[\mathrm{kg} / \mathrm{m}^{3}\right]}\end{array}$} & \multirow{2}{*}{790} \\
\hline \multirow{2}{*}{$n[-]$} & \multirow{2}{*}{0.37} & & \\
\hline & & \multirow{2}{*}{$\begin{array}{c}C p \\
{[\mathrm{~J} /(\mathrm{kg} \cdot \mathrm{C})]}\end{array}$} & \multirow{2}{*}{2500} \\
\hline \multirow{2}{*}{$T,\left[{ }^{\circ} \mathrm{C}\right]$} & \multirow{2}{*}{190} & & \\
\hline & & & \multirow{2}{*}{0.18} \\
\hline$b[1 / \% \mathrm{C}]$ & 0.02 & {$[\mathbf{W} /(\mathbf{m}, \mathbf{K})]$} & \\
\hline
\end{tabular}

Table 3. Material properties - HDPE

This material was much more viscous (its MFI is about .3). When such a material flows through the mixing element there was a coupling of two effects. The first one was mixing as in the previous case and the second one was the dissipation.

\section{Modeling}

The inlet temperature was set as a temperature field in the range of $220^{\circ} \mathrm{C}$ to $200^{\circ} \mathrm{C}$. The temperature contours are shown in Figure 2. As can be seen, the hottest melt was in the center of the inlet channel and the walls were set as the coolest place with constant temperature $200{ }^{\circ} \mathrm{C}$. The aim of this was to see the changes in the temperature field. This can helped understand the behavior of the fluted mixing element. There were two expected effects. One was the cooling/heating of the material while going through the mixing element. The second one was the homogenization of the temperature field. The temperature homogenization was given partially by the conductivity but mainly by mixing. Such a mixing corresponded to a pure blending and it was based on particle displacement only. It was not say anything about breaking particles inside the element etc. If it was found that the mixer homogenized temperature well it means that it would also mix compatible materials with similar viscosities.

The temperature change in the average temperature showed how much the material generated heat and how much heat was conducted through the wall, mainly the barrel.

For the LDPE material with its low viscosity we could expect that the dissipation will be low and thus the temperature changes were given mainly by the heat transfer. For the HDPE material we have a combination of both effects.

$$
\eta(\dot{\gamma}, T)=A f(T) \dot{\gamma}^{n-1}
$$


Table 7. Temperature Difference Comparison - Closed Mixer

Inlet

Outlet

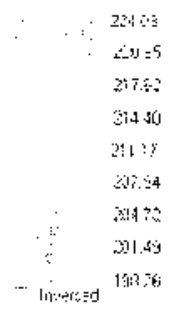

Figure 2. Inlet and outlet temperature profile

\section{Results}

The difference in the average inlet and outlet temperatures, $A T$, as a function of the screw rotation and the fluted mixer gap are given in Tables 4-7. Tables 4-5 contain the results for the LDPE material, while Tables 6- 7 provide the results for a comparison with the HDPE material for the undercut gap 1 .Omm. As can be seen from the calculated data summarized in Tables 4-7, the value $A T$ differs significantly between the open and closed fluted mixers even if the corresponding processing conditions are identical.

\begin{tabular}{|c|c|c|c|}
\hline $\begin{array}{c}\text { Mixer Gialp } \\
\text { [mut }\end{array}$ & רוני & $\begin{array}{c}\Delta T{ }^{\circ} \mathrm{C} \\
\mathrm{n}=60 \mathrm{r} \mathrm{r}^{\circ} \mathrm{m}\end{array}$ & $\mathrm{n}=90 \mathrm{mpm}$ \\
\hline 0.5 & -128 & -89 & -6.6 \\
\hline 1.0 & -8.9 & -5.7 & -4.0 \\
\hline 1.5 & $-\vec{A}$ & -4.5 & -3.1 \\
\hline
\end{tabular}

Table 5 Temperature Diference Closed Mixer

\begin{tabular}{|c|c|c|c|}
\hline \multirow{2}{*}{$\begin{array}{c}\text { Mliser Giap } \\
\text { [mon| }\end{array}$} & \multicolumn{3}{|c|}{$\Delta T^{\circ} \mathrm{C} \mid$} \\
\hline & $\mathrm{a}=3 \mathrm{ar}[\mathrm{mm}$ & $\mathrm{n}=60 \mathrm{r}$ & it $=90 \mathrm{rpm}$ \\
\hline 0.5 & -13.5 & -11.1 & -9.4 \\
\hline$[.9$ & -12.5 & .9 .5 & -7.8 \\
\hline 1.5 & -12.0 & -9.1 & $-7,5$ \\
\hline
\end{tabular}

Table 6. Temperature Difference Comparison - Open M ixer

\begin{tabular}{|c|c|c|}
\hline \multirow{2}{*}{$\begin{array}{c}\text { Mixer Ciap } \\
1.0 \mathrm{~mm}\end{array}$} & \multicolumn{2}{|c|}{$\Delta f^{\circ} \mid \mathrm{Cl}$} \\
\hline & HDPE _.. & LDPE \\
\hline $\mathrm{n}=30$ rpm & -2.3 & -8.9 \\
\hline$n-6)$ & 2.5 & -5.7 \\
\hline $\mathbb{A l}=90 \mathrm{r}[\mathrm{Ju}$ & 5.7 & -40 \\
\hline
\end{tabular}

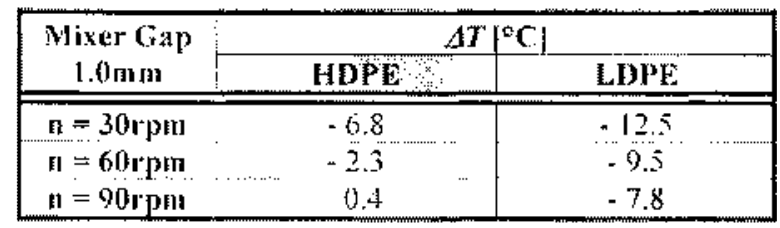

The highest temperature drops of LDPE occurred for the lowest screw rotations because the melt had the longest residence time allowing a more effective heat flux through the walls.

A comparison of temperature changes for both materials indicated that temperature decreased for all screw rotations for LDPE, while for HDPE the sign of the temperature change depended on screw rotations. Temperature decreased for slow rotations and increased for the highest one. This means that the dissipation was higher than the cooling. A comparison of values for LDPE and HDPE also showed that HDPE temperature drop is much higher than for LDPE. This was because of the dissipation in the HDPE material. If we subtracted the temperature difference for the LDPE material from the value for the HDPE one this gave the temperature rise because of the dissipation. It can be seen that the difference is in all cases about $7^{\circ} \mathrm{C}$.

Interestingly, the open fluted mixer had always lower temperature drops $A T$ than the closed one. This can be explained by a presence of a layer, which was rotating very close to the barrel and it was not wiped by the flight. The polymer melt has a low thermal conductivity and the layer functioned as an insulation layer. Thus, the layer restricted heat flux through the walls. A flow path of a particle from the insulation (not wiped) layer is shown in Figure 3.

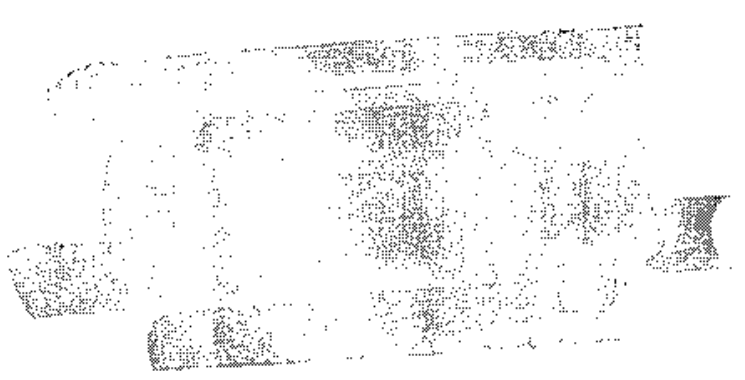

Figure 3. Visualization of a flow path of a particle from the insulation layer for the open fluted mixer

It should be also mentioned that the residence time of the particles in the insulation layer was six times longer than residence time of other particles and the shear stress in this layer was found to be less than $20 \mathrm{kPa}$. A low shear stress may lead to polymer melt degradation [13]. The shear stress profile along the flow path of the particle in the insulation layer is shown in Figure 4. 


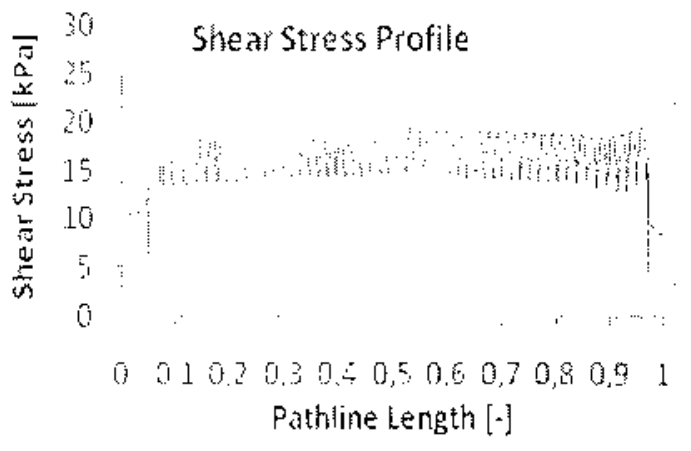

Figure 4. Shear stress profile for a particle from the insulation layer

A comparison of the behavior of a mixing element with and without the wiping flight showed that there was a difference in the mixing element behavior and that the mixing element without the wiping flight had a lower cooling efficiency and much higher residence time, which means it could easier initiate the material degradation.

The second studied effect was the pressure drop on the mixing element. All pressure values were counted from the same path line, which was going through the center of the gap and mixing element. The pressure drop and the barrier pressure drop on the open mixer are shown in Table 8 and Table 9. As can be seen, the pressure drop of the most closed gap was almost three times bigger than on the open gap. The path line position was chosen in a way that the shear stress was not dominant and therefore the influence of the drag flow was the controlling factor. The pressure drop went down with the increase of screw rotations and also with opening the gap. The barrier pressure drop shown in Figure 5 in a highlighted rectangle shows what part of the overall pressure drop was consumed during the flow over the undercut. There were local maxima when the material was comes close to the barrel and minima when the material was at the bottom of the channel. The highest drop was over the barrier.

Table 8. T'ressure Drop Opeth Mixer

\begin{tabular}{|c|c|c|c|}
\hline \multirow{2}{*}{$\begin{array}{c}\text { Mixer Galp } \\
\text { |mm }\end{array}$} & \multicolumn{3}{|c|}{ Pressiate Drop IMPal } \\
\hline & $n=30 \mathrm{rpm}$ & $n=69 r p m$ & $\mathbf{n}=90 \mathrm{rp} \equiv \mathbf{1}$ \\
\hline 0.5 & 1.66 & 1.5 & 1.13 \\
\hline 1.0 & 0.50 & 0.68 & 0.75 \\
\hline 1.5 & 0.45 & 0.55 & 0.62 \\
\hline
\end{tabular}

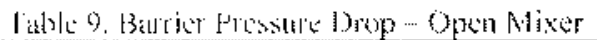

\begin{tabular}{|c|c|c|c|}
\hline \multirow{2}{*}{$\begin{array}{c}\text { Mixer Giap } \\
\text { |mint }\end{array}$} & \multicolumn{3}{|c|}{ Barrier Pressure Drop $\mid \mathrm{MP}$ al } \\
\hline & 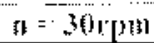 & $\mathrm{n}=61 \mathrm{~s} n \mathrm{pm}$ & $\mathrm{n}=9 \mathrm{fipm}$ \\
\hline 11.5 & 1.11 & 1.04 & 0.95 \\
\hline 1.0 & 0.20 & 0.33 & 0.23 \\
\hline 1.5 & 0.1 at & 0.15 & 0,16 \\
\hline
\end{tabular}

Pressure Drop - Open Mixer

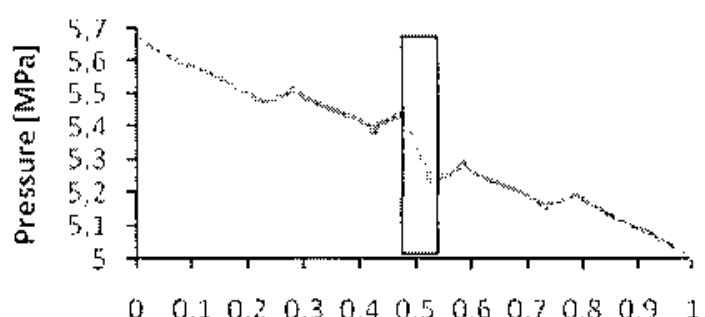

Pathline Length [-]

Figure 5. Pressure profile through the open fluted mixer

The pressure drop on the closed mixer is shown in Tables 10 and 11. It can be seen that the situation was completely different from results for the open mixer. The barrier pressure drop became sometime negative. Therefore, pressure was generated while the material flowed through the gap on the closed mixer. It is demonstrated in figure 6. As displayed in Figure 6, pressure decreased again until the undercut area, which is represented by a yellow rectangle, where the pressure rose. The local minima and maxima were again close to the screw or the barrel surface. The pressure drop also increased more for higher screw rotation and the gap size. Pressure was consumed for the smallest gap.

Table 10« Pressure Drop - Closed Mixer

\begin{tabular}{|c|c|c|c|}
\hline \multirow{2}{*}{$\begin{array}{c}\text { Mixer Gap } \\
\text { |mm| }\end{array}$} & \multicolumn{3}{|c|}{ Pressere Drop [M1Pa] } \\
\hline & $\mathrm{n}=30 \mathrm{rpm}$ & $\mathrm{n}=60 \mathrm{0rpm}$ & $\mathrm{n}=90 \mathrm{rpm}$ \\
\hline 0.5 & 0.53 & 0.64 & 0.72 \\
\hline 1.0 & 0.14 & 0.20 & 0.25 \\
\hline 1.5 & 0.08 & 0.14 & 0.20 \\
\hline
\end{tabular}

Table 11. Barrier Pressure Drop -.. Closed Mixer

\begin{tabular}{|c|ccc|}
\hline $\begin{array}{c}\text { Mixer Gap } \\
|\mathrm{mm}|\end{array}$ & \multicolumn{3}{|c|}{ Barrier Pressure Drop |MPa| } \\
\hline 0.5 & 0.13 & 0.17 & 0.18 \\
1.0 & -0.15 & -0.18 & -0.18 \\
1.5 & -0.21 & -0.23 & -0.26 \\
\hline
\end{tabular}


Pressure Drop - Closed Mixer

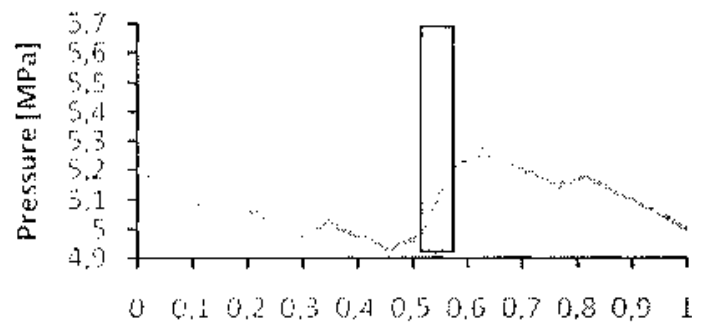

Pathline Length [-]

Figure 0. Pressure profile through the closed fluted mixer

Fable 12, Pressure Drop Comparison

\begin{tabular}{|c|c|c|c|c|}
\hline \multirow{3}{*}{$\begin{array}{c}\text { Vixce Gap } \\
\text { l.0mal }\end{array}$} & \multicolumn{4}{|c|}{ Plessure Dtop , MPal } \\
\hline & \multicolumn{2}{|c|}{ HDPF } & \multicolumn{2}{|c|}{ IDPE } \\
\hline & O|M̈11 & Closed & Opent & C.10st \\
\hline ll $=3[]^{2}$ prit & 3.91 & -0.39 & 0.96 & 0.14 \\
\hline $1 \mid=60 \mathrm{Fpur}$ & 4.86 & -0.3 & 068 & 0.20 \\
\hline 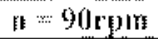 & 5.51 & -0.61 & 0.75 & 0.25 \\
\hline
\end{tabular}

Table 13. Barrirer Pressure Drop Comparison

\begin{tabular}{|c|c|c|c|c|}
\hline \multirow{3}{*}{ 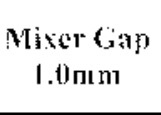 } & \multicolumn{4}{|c|}{ Barrice Pressule DroplMPa] } \\
\hline & \multicolumn{2}{|c|}{$\left.|| D\right|^{\prime}$} & \multicolumn{2}{|c|}{ LDPF } \\
\hline & Ophin & Clused & $0 p+11$ & Closed \\
\hline $\mathrm{rl}=3 \mathrm{tr} \mathrm{r}_{\mathrm{j}} \mathrm{m}$ & 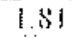 & -1.9 & 0.20 & -0.15 \\
\hline$\Gamma=60(\mathrm{r}) \mathrm{nt}$ & 2.37 & -2.13 & 4.23 & -0.18 \\
\hline $\mathrm{I}=9 \mathrm{ar} \mathrm{jm}$ & $25 \overline{7}$ & -7.75 & 0.23 & -0.18 \\
\hline
\end{tabular}

A comparison of the pressure drops for a $1 \mathrm{~mm}$ gap on both types of mixers is shown in Tables 12 and $\mathbf{1 3}$. It can be seen that the pressure drop on the closed mixer was always higher than on the open mixer. As has been demonstrated by previous tables for LDPE, the open and closed mixers behave differently. The pressure behavior of the more viscous HDPE in the open and closed configuration was similar to LDPE. Pressure drop and barrier pressure drop profiles had a similar trend like for LDPE but the values were higher because of the material viscosity.

In the final stage of the research, the mixing efficiency of the closed and open fluted mixers was investigated by a $k$ parameter, which is defined as:

$$
\lambda=\frac{|\omega|+|D|}{|D|}
$$

Where $D$ is the deformation rate tensor and $c o$ is the vorticity tensor. The mixing coefficient $X$ was calculated along the same path line as the pressure and is depicted in Figure 7.
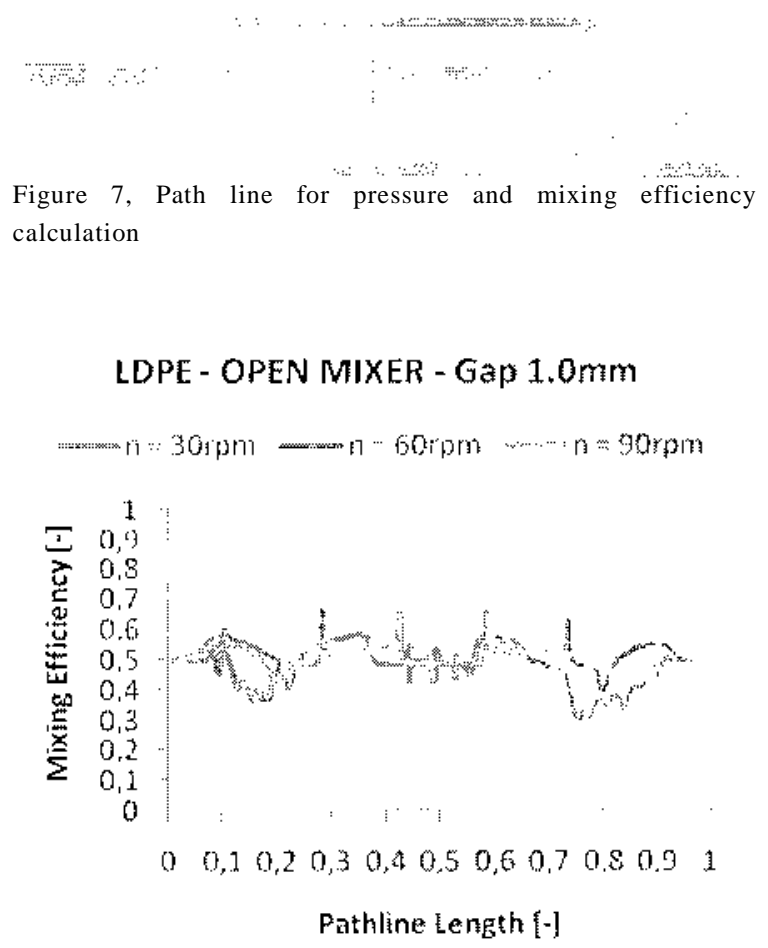

Figure 8. I DPK Mixing efficiency of the open fluted mixing element

HDPE - OPEN IVIIXER - Gap 1,0mm

n 3 Or pm - - n 6th pm n 9 Or pm

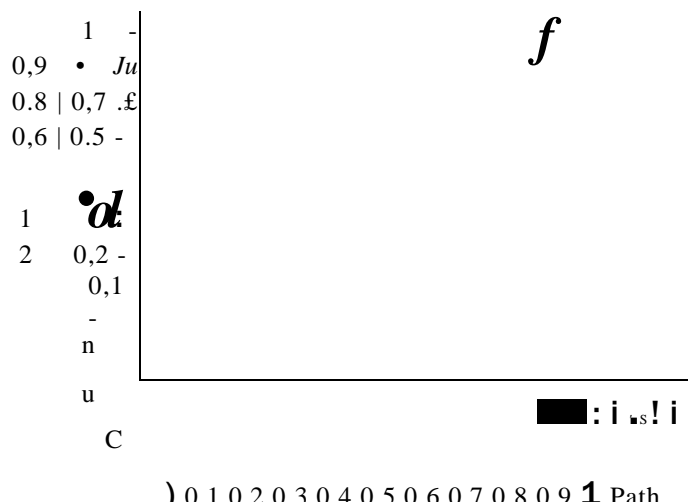

Figure 9, HDPE Mixing efficiency of the open fluted mixing element

Figures 8-1 1 show the calculated mixing efficiency parameter $\boldsymbol{X}$ for $1.0 \mathrm{~mm}$ gap on the open and closed fluted mixer elements. Interestingly, the mixing efficiency is almost the same in all cases. Thus, the geometry changes 
and material properties did not have any impact to mixing efficiency parameter.

It can be seen that the parameter $X$ was in most cases around a value.5, which means the shearing. This confirmed that the majority on both cases of the mixers was the shear mixing.

\section{LDPE - CLOSED MIXER - Gap 1.0mm}

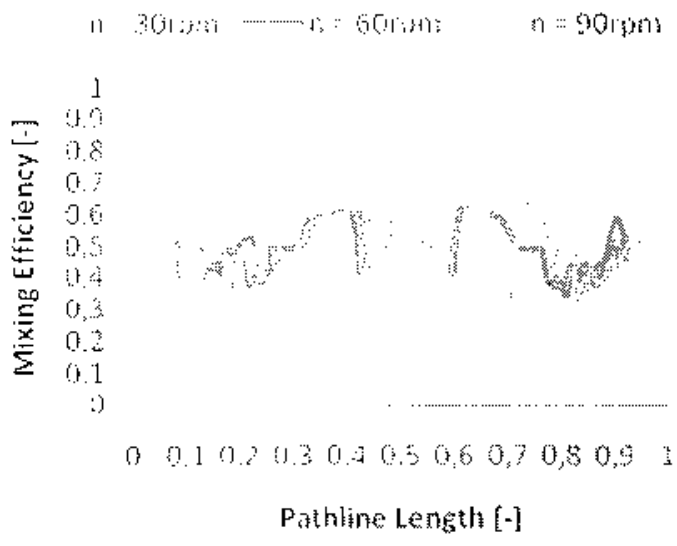

Figure H). LOPE Mixing efficiency of the closed fluted mixinu element

HDPE - CLOSED MIXER - Gap $1.0 \mathrm{~mm}$

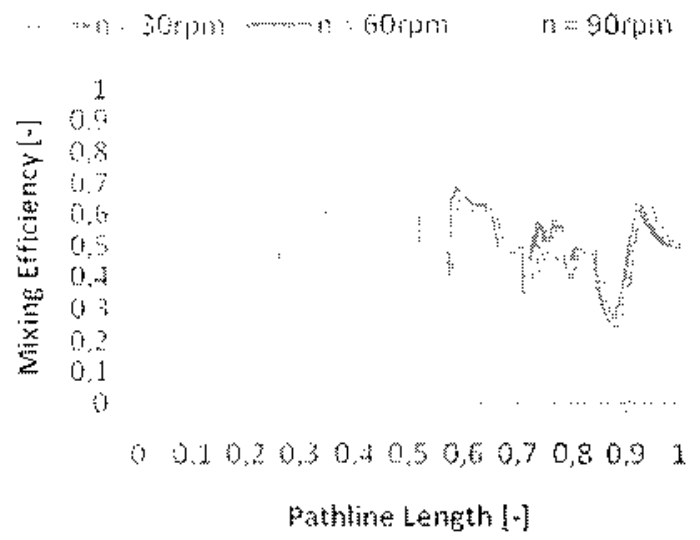

Figure IK IIDPF. Mixing efficiency of ihe closed fluted mixitm element

\section{Resume}

The simulations performed show different behavior of the open and closed fluted mixers. The main reason of this difference is the existence of insulation layer for the open mixer. This layer is located at the barrel surface and it works as a barrier of the heat transfer. On the other side, since the layer is there it occupies certain part of the gap over the undercuts and thus it makes the gap effectively smaller than for the closed mixer. This layer is wiped out in the closed mixer. It has been found that the shear stress in the insulation layer is lower than $20 \mathrm{kPa}$, which may lead to polymer melt degradation. Pressure profiles and pressure drops depend also on the material type, gap size and the speed of rotation. The analysis clearly shows that the mixing efficiency defined by the $X$ parameter is independent on the material properties and the geometry variations of the fluted mixer.

\section{References}

1. A. L. Kelly, E. C. Brown and P. D. Coates, Polymer Engineering and Science 46, 1706-1714 (2006).

2. M. E. Ghir, C. G. Gogos, D. W. YU, D. B. Todd and B. David, Advances in Polymer Technology 17, 1-17 (1998).

3. D. Strutt, C. Tzoganakis and T. A. Duever, Polymer Engineering and Science 40, 992-1003 (2000).

4. G. Shearer and C. Tzoganakis, Advances in Polymer Technology 20, 169-190 (2001).

5. D. Strutt, C. Tzoganakis and T. A. Duever, Advances in Polymer Technology 19, 22-33 (2000).

6. M. A. Huneault, M. F. Champagne and A. Luciani, Polymer Engineering and Science 36, 1694-1706 (1996).

7. V. L. Bravo and A. N. Hrymak, Polymer Engineering and Science, 40, 525-541 (2000).

8. V. L. Bravo, A. N. Hrymak and J. D. Wright, Polymer Engineering and Science 44, 779-793 (2004).

9. R. Valette, T. Coupez, C. David and B. Vergnes, International Polymer Processing 24, 141-147 (2009).

10. T. Ishikawa, et al., International Polymer Processing 21, 354-360 (2006).

11. Ch. Rauwendall, Polymer Extrusion, Munich: Carl Hanser Verlag, 1990.

12. http://www.compuplastvel.com

13. M. Zatloukal, J. Vlcek, A. Slanik, A. Lengalova and J. Simonik, Applied Rheology 12, 126-132 (2002).

Key Words: Fluted Mixer, Insulation Layer, 3D Finite Element Method Simulation 